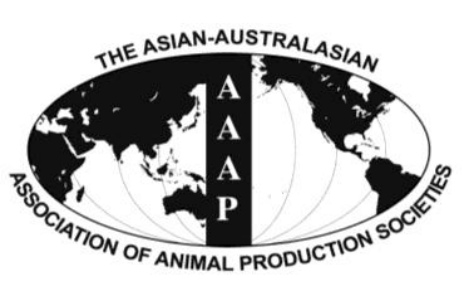

Open Access

\begin{tabular}{c} 
Open Access \\
Asian Australas. J. Anim. Sci. \\
Vol. 27, No. 4 : 537-542 April 2014 \\
http://dx.doi.org/10.5713/ajas.2013.13706 \\
\hline www.ajas.info \\
pISSN 101 1-2367 elSSN 1976-5517
\end{tabular}

\title{
Cholesterol Removal from Whole Egg by Crosslinked $\beta$-Cyclodextrin
}

\author{
H. J. Jeong, H. Sun, C. Chogsom, and H. S. Kwak* \\ Department of Food Science and Technology, Sejong University, Seoul 143-747, Korea
}

\begin{abstract}
This study was carried out to optimize cholesterol removal in whole egg using crosslinked $\beta$-cyclodextrin ( $\beta$-CD) and to recycle the $\beta-C D$. Various factors for optimizing conditions were concentration of the $\beta-C D$, mixing temperature, mixing time, mixing speed and centrifugal speed. In the result of this study, the optimum conditions of cholesterol removal were $25 \%$ crosslinked $\beta$-CD, $40^{\circ} \mathrm{C}$ mixing temperature, $30 \mathrm{~min}$ mixing time, 1,200 rpm mixing speed and 2,810×g centrifugal speed. The recycling was repeated five times. The cholesterol removal was $92.76 \%$ when treated with the optimum conditions. After determining the optimum conditions, the recyclable yields of the crosslinked $\beta$-CD ranged from $86.66 \%$ to $87.60 \%$ in the recycling and the percentage of cholesterol removal was over $80 \%$ until third recycling. However, the cholesterol removal efficiency was decreased when the number of repeated recycling was increased. Based on the result of this study, it was concluded that the crosslinked $\beta-C D$ was efficient for cholesterol removal in whole egg, and recycling is possible for only limited repeating times due to the interaction of the $\beta$-CD and egg protein. (Key Words: Cholesterol Removal, Crosslinked $\beta$-Cyclodextrin, Whole Egg)
\end{abstract}

\section{INTRODUCTION}

Cholesterol is necessary for maintaining life and is used in all cells of the body, it is an essential component of cell membranes and is a precursor of steroid hormone; it helps to absorb and digest fat and plays an important role in the formation of vitamin D. However, higher cholesterol concentrations have long been associated with a higher risk of cardiovascular diseases (CVD). If there is too much serum cholesterol, it tends to accumulate on the walls of the blood vessels, forming plaque and narrowing the blood vessels, which in some cases could promote heart attack, stroke and blood clotting (Rahkovsky and Gregory, 2013). Therefore, consumers are increasingly concerned about excessive intakes of cholesterol and it was recommended that the total cholesterol intake should be less than 300 $\mathrm{mg}$ /day (Brown, 1990). Egg intake increases LDL- and HDL cholesterol in body, but this change is relatively small. One egg per day in a diet was not related to heart disease

\footnotetext{
* Corresponding Author: H. S. Kwak. Tel: +82-2-3408-3226, Fax: +82-2-3408-4319, E-mail: kwakhs@ sejong.ac.kr Submitted Nov. 8, 2013; Accepted Jan. 14, 2014; Revised Jan. 21, 2014
}

(McNamara, 2013). Most healthy people were not at risk of CVD or increased mortality when they eat eggs. However, diabetic patients were at an increased risk of CVD because of a small change in circulating cholesterol after egg intake (Shin et al., 2013).

From ancient times, eggs have been an important source of high quality protein, other beneficial nutrients, and also a primary source of dietary cholesterol. Eggs from all species of poultry consists of 52\%-58\% egg white, $32 \%-35 \%$ egg yolk and 9\%-14\% shell, and contain about 200-250 mg cholesterol (Griffin, 1992; Mine, 2008). Catering to the consumers' demands, food companies attempt to reduce cholesterol in a wide variety of food, and they have investigated different approaches to reduce cholesterol in eggs, such as hypocholesterolemic agent administration (Hargis, 1988; Griffin, 1992) extraction with solvents (Melnick, 1971; Merchant et al., 1991) or oils (Frioriti et al., 1978) and supercritical fluid extraction (Haberstroh and Morris, 1991). The removal of cholesterol by absorption with $\beta-C D$ is an alternative approach (Smith et al., 1995) used to produce cholesterol-reduced egg products $(80 \%$ cholesterol free), based on a patent of reported by Cully and Vollbrecht (1990), that was marketed briefly in the US. 
According to previous study (Kim et al., 2004), it was reported that the crosslinked $\beta$-CD made with adipic acid exhibited higher cholesterol removal than $\beta$-CD in milk, it was also reported that the $\beta$-CD removed over $90 \%$ of cholesterol from egg yolk diluted with water (1:1) and that the $\beta$-CD could be recovered and recycled for further use (Jung et al., 2005). Therefore, this method could be applied in industrial food processing. But the separation of egg components in the food industry is a complex process which sometimes involves undesirable property changes. Therefore, the objective of this study was to optimize cholesterol removal from whole egg by crosslinked $\beta-\mathrm{CD}$.

\section{MATERIALS AND METHODS}

\section{Materials}

Eggs were purchased from a retail store with the average size of $62.67 \pm 0.25 \mathrm{~g}$ and powdered crosslinked $\beta-C D$ was obtained from MSC Co. (Yangsan, Korea). Hexane (purity 95\%), potassium hydroxide (purity 95\%) and ethanol (purity 95\%) were obtained from Samchun Chemical Co. Ltd. (Pyongtack, Korea). Cholesterol (purity 99\%) was purchased from Sigma Chemical Co. (St Louis, MO, USA).

\section{Proximate composition}

The compositions of whole egg were analyzed for water, crude protein, total carbohydrate, total lipid and ash according to the method of Association of Official Analytical Chemists (AOAC, 2000).

\section{Cholesterol removal from whole egg}

After removing the egg shell, whole eggs were mixed and sieved. Whole egg $(100 \mathrm{~g})$ was placed in $300 \mathrm{~mL}$ beaker and crosslinked $\beta$-CD was added to give final concentrations of $10 \%, 15 \%, 20 \%, 25 \%$, and $30 \%(\mathrm{w} / \mathrm{v})$. The mixture was stirred at various speeds $(400,600,800$, and 1,200 rpm) with a blender (Tops; Misung Co., Seoul, Korea). This process was performed in a temperature controlled water bath at different mixing temperatures $\left(30^{\circ} \mathrm{C}, 35^{\circ} \mathrm{C}, 40^{\circ} \mathrm{C}, 45^{\circ} \mathrm{C}\right.$, and $\left.50^{\circ} \mathrm{C}\right)$ for different times $(20$, $30,40,50$, and $60 \mathrm{~min})$. The mixture was centrifuged (HMR-220IV; hanil Industrial Co., Seoul, Korea) at different speeds $(2,210,2,810,3,440,4,140$, and $4,900 \times \mathrm{g})$ for $10 \mathrm{~min}$. All treatments were repeated 3 times.

\section{Extraction and quantification of cholesterol from whole egg}

The extraction of cholesterol was achieved using the modified method of Adams et al. (1986). Crosslinking of $\beta$-CD was made according to the method of Han et al. (2007). One gram of the crosslinked $\beta$-CD-treated whole egg was placed in screw-capped glass tube $(15 \times 180 \mathrm{~mm})$. The sample was saponified at $60^{\circ} \mathrm{C}$ for $30 \mathrm{~min}$ with $5 \mathrm{~mL}$ of $2 \mathrm{M}$ ethanolic potassium hydroxide solution. After cooling to room temperature, cholesterol was extracted with $5 \mathrm{~mL}$ of hexane. The process was repeated four times. The hexane layer was transferred to a round bottomed flask and dried under vacuum. The extract was re-dissolved in $1 \mathrm{~mL}$ of hexane.

Total cholesterol was measured on a silica fused capillary column (HP-1, $25 \mathrm{~m} \times 0.32 \mathrm{~mm}$ I.D. $\times 0.17 \mu \mathrm{m}$ thickness) using a Donam gas chromatography (Seoul, Korea) equipped with a flame ionization detector. The injector and detector temperatures were $270^{\circ} \mathrm{C}$ and $300^{\circ} \mathrm{C}$, respectively. The oven temperature was programmed to increase from $200^{\circ} \mathrm{C}$ to $300^{\circ} \mathrm{C}$ at $10^{\circ} \mathrm{C} / \mathrm{min}$ and then was maintained for $20 \mathrm{~min}$. Nitrogen was used as carrier gas at a flow rate of $2 \mathrm{~mL} / \mathrm{min}$ with a split ratio of 1:50. The injected sample volume was $2 \mu \mathrm{L}$. Quantification of cholesterol was done by comparing the peak area with the standard curve. The percentage of cholesterol reduction was calculated as follows:

\section{Cholesterol reduction (\%) \\ $=100-$ the amount of cholesterol in the crosslinked $\beta$-CD-treated whole egg $\times 100 /$ the amount of cholesterol in the untreated whole egg (control)]}

\section{Yield of recyclable crosslinked $\beta$-CD}

The cholesterol-entrapped crosslinked $\beta-\mathrm{CD}$ was mixed with ethanol in a conical flask $(500 \mathrm{~mL})$ at $100 \mathrm{rpm}$ stirring speed using a hot plate magnetic stirrer (Misung Scientific Co., Ltd, Seoul, Korea) for $1 \mathrm{~h}$ at boiling point, and the ratio of compound to solvent was 1:4. The sample was then cooled to room temperature and centrifuged at $6,300 \times \mathrm{g}$ for $5 \mathrm{~min}$. The precipitated crosslinked $\beta-\mathrm{CD}$ was dried at $60^{\circ} \mathrm{C}$ in dry oven for $6 \mathrm{~h}$ and reused for this recycling study. The recyclable yields of crosslinked $\beta-\mathrm{CD}$ were calculated as follows:

$$
\begin{aligned}
& \text { Yield }(\%) \\
& =(\text { Recovered amount of crosslinked } \beta-\mathrm{CD} \text { after recycle } \\
& \quad / \text { Initial amount of } \beta-\mathrm{CD}) \times 100
\end{aligned}
$$

\section{Statistical analysis}

Data from each experiment were analyzed using SAS version 9.0 (SAS Institute Inc., 2002). An ANOVA was performed by the general linear models procedure to determine between the samples. Means were compared by using Duncan's method. A significance level was set at $p<0.05$. 


\section{RESULTS}

\section{Proximate composition of whole egg}

The proximate composition of whole egg was water $74.81 \pm 0.06 \mathrm{~mL}$, crude protein $13.52 \pm 0.32 \mathrm{~g}$, total carbohydrate $0.67 \pm 0.12 \mathrm{~g}$, total lipid $8.92 \pm 0.12 \mathrm{~g}$, ash $0.79 \pm 0.26$ g per 100 gram and cholesterol $448 \pm 0.25 \mathrm{mg}$ per $100 \mathrm{~g}$.

\section{Effect of crosslinked $\beta-C D$ concentrations}

The various concentrations of the crosslinked $\beta-\mathrm{CD}$ $(10 \%, 15 \%, 20 \%, 25 \%$, and $30 \%$; W/V) were applied into whole egg to optimize cholesterol removal as shown in Table 1. The concentrations of the $\beta-\mathrm{CD}$ removed cholesterol from $80.08 \%$ to $91.88 \%$ when mixed at $40^{\circ} \mathrm{C}$ for $30 \mathrm{~min}$ with $800 \mathrm{rpm}$. There was no significant difference between $25 \%$ and $30 \%$, and cholesterol removals were $91.88 \%$ and $90.21 \%$ ( $p>0.05$ ), respectively. Therefore, the result indicated that $25 \%$ crosslinked $\beta-C D$ may be a suitable amount to remove cholesterol effectively in whole egg.

\section{Effect of mixing temperature}

The effect of cholesterol removal from whole egg by the crosslinked $\beta-\mathrm{CD}$ with the various mixing temperatures $\left(30^{\circ} \mathrm{C}, 35^{\circ} \mathrm{C}, 40^{\circ} \mathrm{C}, 45^{\circ} \mathrm{C}\right.$, and $\left.50^{\circ} \mathrm{C}\right)$ is shown in Table 2 . The different mixing temperatures had an effect on cholesterol removals from $87.85 \%$ to $90.96 \%$ when treated with $25 \%$ crosslinked $\beta-C D$ at $800 \mathrm{rpm}$ mixing speed for 30 min with $2,810 \times \mathrm{g}$ centrifugal speed. Differences of cholesterol removal were not significant among $40^{\circ} \mathrm{C}, 45^{\circ} \mathrm{C}$, and $50^{\circ} \mathrm{C}(\mathrm{p}>0.05)$, and the cholesterol removals were in the range of $89.54 \%$ to $90.96 \%$. Therefore, this study concluded that $40^{\circ} \mathrm{C}$ is the optimal temperature for cholesterol removal from whole egg.

\section{Effect of mixing time}

The effect of various mixing times $(20,30,40,50$, and

Table 1. Effect of various crosslinked $\beta$-cyclodextrin concentrations on cholesterol removal from whole egg ${ }^{1}$

\begin{tabular}{lc}
\hline $\begin{array}{l}\text { Concentration of } \\
\text { crosslinked } \beta-C D(\%)\end{array}$ & Cholesterol removal (\%) \\
\hline 10 & $80.0 \pm 0.3^{\mathrm{d}}$ \\
15 & $87.2 \pm 2.5^{\mathrm{c}}$ \\
20 & $88.5 \pm 2.1^{\mathrm{bc}}$ \\
25 & $91.9 \pm 0.6^{\mathrm{a}}$ \\
30 & $90.2 \pm 0.2^{\mathrm{ab}}$ \\
\hline
\end{tabular}

${ }^{1}$ Conditions for cholesterol removal; mixing temperature; $40^{\circ} \mathrm{C}$, mixing time; 30 min, mixing speed; $800 \mathrm{rpm}$, centrifugal speed; 2,810 $\times \mathrm{g}$. All samples were repeated 3 times.

a-d Values with different superscripts within the same column differ significantly $(\mathrm{p}<0.05)$.
Table 2. Effect of various mixing temperatures on cholesterol removal from whole egg using crosslinked $\beta$-cyclodextrin ${ }^{1}$

\begin{tabular}{lc}
\hline Mixing temperature $\left({ }^{\circ} \mathrm{C}\right)$ & Cholesterol removal $(\%)$ \\
\hline 30 & $87.85 \pm 5.86^{\mathrm{c}}$ \\
35 & $88.60 \pm 4.75^{\mathrm{c}}$ \\
40 & $90.96 \pm 3.43^{\mathrm{a}}$ \\
45 & $89.88 \pm 4.59^{\mathrm{ab}}$ \\
50 & $89.54 \pm 6.92^{\mathrm{abc}}$ \\
\hline${ }^{1}$ Conditions for cholesterol removal; crosslinked $\beta-\mathrm{CD} ; 25 \%$, mixing \\
time; 30 min, mixing speed; 800 rpm, centrifugal speed; 2,810×g. All \\
samples were repeated 3 times. \\
a-c Values with different superscripts within the same column differ \\
significantly (p<0.05).
\end{tabular}

$60 \mathrm{~min}$ ) used to optimize cholesterol removal by the crosslinked $\beta-\mathrm{CD}$ are shown in Table 3. In this study, a significantly greater $(\mathrm{p}<0.05)$ cholesterol removal of 93.44\% was observed at the 30 min mixing time. However, other mixing times also achieved over $90 \%$ cholesterol removal from $25 \%$ crosslinked $\beta$-CD at $40^{\circ} \mathrm{C}$ with $800 \mathrm{rpm}$

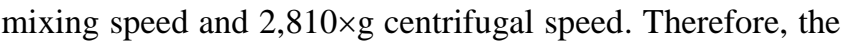
result concluded that the optimum mixing time is $30 \mathrm{~min}$.

\section{Effect of mixing speed}

The effect of mixing speeds $(400,600,800,1,000$, and $1,200 \mathrm{rpm}$ ) on cholesterol removal efficiency is shown in

Table 3. Effect of various mixing times on cholesterol removal from whole egg using crosslinked $\beta$-cyclodextrin ${ }^{1}$

\begin{tabular}{lc}
\hline Mixing time (min) & Cholesterol removal (\%) \\
\hline 20 & $90.74 \pm 3.90^{\mathrm{b}}$ \\
30 & $93.44 \pm 2.26^{\mathrm{a}}$ \\
40 & $90.76 \pm 0.38^{\mathrm{b}}$ \\
50 & $90.46 \pm 0.92^{\mathrm{b}}$ \\
60 & $90.02 \pm 0.57^{\mathrm{b}}$ \\
\hline
\end{tabular}

${ }^{1}$ Conditions for cholesterol removal; crosslinked $\beta$-CD; $25 \%$, mixing temperature; $40^{\circ} \mathrm{C}$, mixing speed; $800 \mathrm{rpm}$, centrifugal speed; $2,810 \times \mathrm{g}$. All samples were repeated 3 times.

${ }^{a, b}$ Values with different superscripts within the same column differ significantly $(\mathrm{p}<0.05)$.

Table 4. Effect of various mixing speeds on cholesterol removal from whole egg using crosslinked $\beta$-cyclodextrin ${ }^{1}$

\begin{tabular}{cc}
\hline Mixing speed (rpm) & Cholesterol removal (\%) \\
\hline 400 & $92.4 \pm 0.3^{\mathrm{a}}$ \\
600 & $93.3 \pm 1.5^{\mathrm{a}}$ \\
800 & $93.4 \pm 0.5^{\mathrm{a}}$ \\
1,000 & $90.0 \pm 0.4^{\mathrm{b}}$ \\
1,200 & $89.0 \pm 0.4^{\mathrm{b}}$ \\
\hline
\end{tabular}

Conditions for cholesterol removal; crosslinked $\beta-\mathrm{CD} ; 25 \%$, mixing temperature; $40^{\circ} \mathrm{C}$, mixing time; $30 \mathrm{~min}$, centrifugal speed; $2,810 \times \mathrm{g}$ All samples were repeated 3 times.

a,b Values with different superscripts within the same column differ significantly $(\mathrm{p}<0.05)$. 
Table 4. The cholesterol removal ranged from $88.95 \%$ to $93.43 \%$ when treated with $25 \%$ cross linked $\beta-\mathrm{CD}$ at $40^{\circ} \mathrm{C}$ for $30 \mathrm{~min}$ with $2,810 \times \mathrm{g}$ centrifugal speed. There was no significant difference between 600 and $800 \mathrm{rpm}$, and cholesterol removal was $93.33 \%$ and $93.43 \%$, respectively $(\mathrm{p}<0.05)$. Over $800 \mathrm{rpm}$, the cholesterol removal decreased gradually to $88.95 \%$ at $1,200 \mathrm{rpm}$. Therefore, the result indicated that $800 \mathrm{rpm}$ could be optimal mixing speed.

\section{Effect of centrifugal speed}

The various centrifugal speeds $(2,210,2,810,3,440$, $4,140 \%$ and $4,900 \times \mathrm{g}$ ) were selected to optimize cholesterol removal as shown in Table 5. The cholesterol removal increased up to $92.76 \%$ when centrifugal speed increased to $2,810 \times \mathrm{g}$. However, the cholesterol removal decreased significantly at $3,440 \times \mathrm{g} \quad(\mathrm{p}<0.05)$. Cholesterol removal decreased to $86 \%$ when the centrifugal speed was higher than $3,440 \times \mathrm{g}$. Therefore, this result showed that $2,810 \times \mathrm{g}$ might be the most effective centrifugal speed.

\section{Recyclable yield of crosslinked $\boldsymbol{\beta}-\mathbf{C D}$}

The crosslinked $\beta-\mathrm{CD}$ for recycling was applied to whole egg five times repeatedly and the yield of the crosslinked $\beta$-CD is shown in Figure 1. The recyclable yield of the crosslinked $\beta-\mathrm{CD}$ was found to be between $87.66 \%$ and $86.6 \%$ from one and three time uses with no significant difference $(p>0.05)$. However, a slight increase was shown in fourth and fifth time uses as $92.03 \%$ and $96.74 \%$, respectively. The yields of the crosslinked $\beta-\mathrm{CD}$ in fourth and fifth recycles were even more than the yield following its initial use $(93.69 \%)$ to remove cholesterol from whole eggs.

\section{Cholesterol removal efficiency of recyclable yield of crosslinked $\beta$-CD}

After the optimization of cholesterol removal from whole egg, the cholesterol removal efficiency of the crosslinked $\beta-C D$ in whole egg was examined at 5 repeated times and is presented in Figure 2. Higher cholesterol

Table 5. Effect of various centrifugal speeds on cholesterol removal from whole egg using crosslinked $\beta$-cyclodextrin ${ }^{1}$

\begin{tabular}{lc}
\hline Centrifugal speed $(\times \mathrm{g})$ & Cholesterol removal $(\%)$ \\
\hline 2,210 & $92.5 \pm 1.2^{\mathrm{a}}$ \\
2,810 & $92.8 \pm 1.1^{\mathrm{a}}$ \\
3,440 & $87.0 \pm 4.2^{\mathrm{b}}$ \\
4,140 & $87.0 \pm 0.5^{\mathrm{b}}$ \\
4,900 & $86.5 \pm 10 .^{\mathrm{b}}$ \\
\hline
\end{tabular}

\footnotetext{
Conditions for cholesterol removal; crosslinked $\beta-\mathrm{CD} ; 25 \%$, mixing temperature; $40^{\circ} \mathrm{C}$, mixing time; $30 \mathrm{~min}$, mixing speed; $800 \mathrm{rpm}$. All samples were repeated 3 times.

${ }^{a, b}$ Values with different superscripts within the same column differ significantly $(\mathrm{p}<0.05)$
}

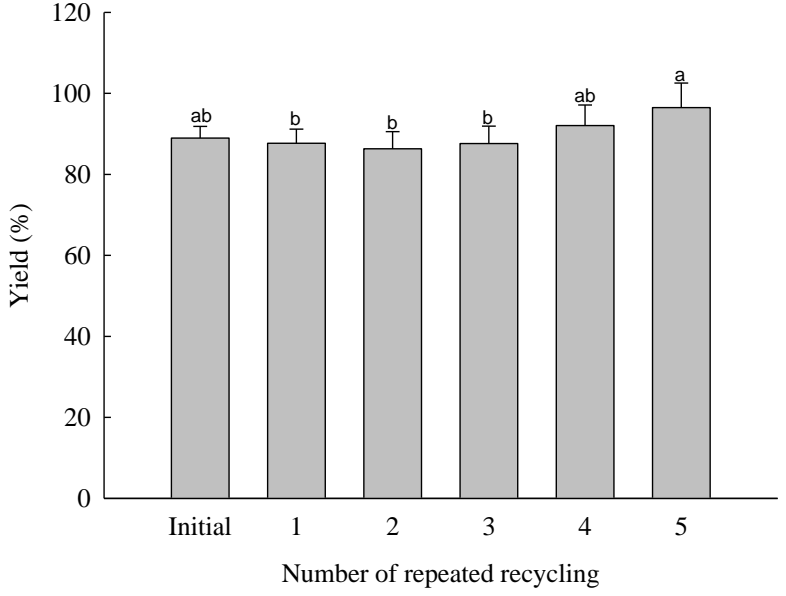

Figure 1. The efficiency of recycled crosslinked $\beta$-cyclodextrin on cholesterol removal from whole egg. Conditions for cholesterol removal; crosslinked $\beta-\mathrm{CD} ; 25 \%$, mixing temperature; $40^{\circ} \mathrm{C}$, mixing time; $30 \mathrm{~min}$, mixing speed; $800 \mathrm{rpm}$, centrifugal speed; $2,810 \times$ g. All samples were repeated 3 times. ${ }^{a, b}$ Values with different superscripts within the same column differ significantly $(\mathrm{p}<0.05)$

removal was found in the range of $86.87 \%$ to $83.75 \%$ when the crosslinked $\beta-\mathrm{CD}$ was used for three times, but cholesterol removal significantly decreased to $70.94 \%$ by the fifth recycle $(\mathrm{p}<0.05)$.

\section{DISCUSSION}

Several studies have investigated the optimum condition for removing cholesterol from different food products including milk (Kim et al., 2004), cream (Han et al., 2007),

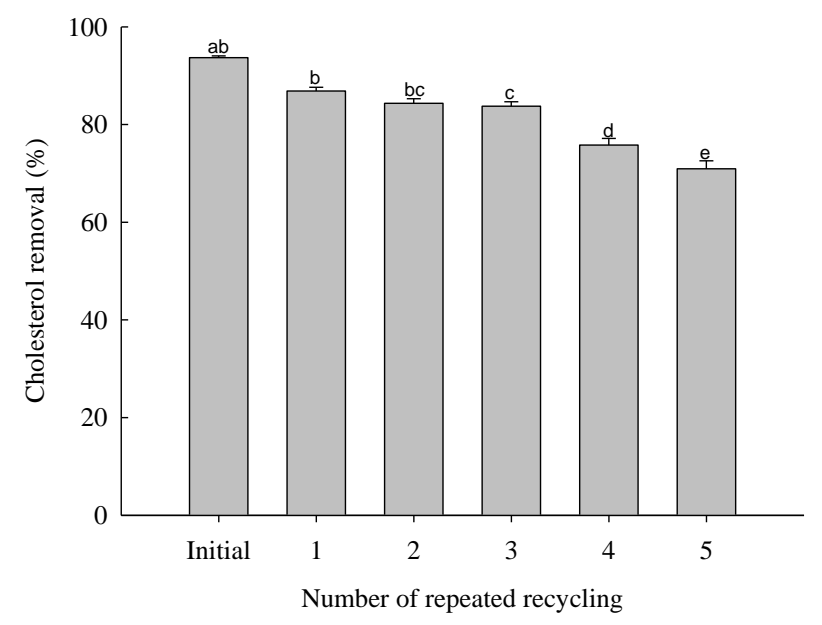

Figure 2. Cholesterol removal using crosslinked $\beta$-cyclodextrin with repeated recycling in whole egg. Conditions for cholesterol removal; crosslinked $\beta-\mathrm{CD} ; 25 \%$, mixing temperature; $40^{\circ} \mathrm{C}$, mixing time; $30 \mathrm{~min}$, mixing speed; $800 \mathrm{rpm}$, centrifugal speed; $2,810 \times$ g. All samples were repeated 3 times. ${ }^{\text {a-e }}$ Values with different superscripts within the same column differ significantly $(\mathrm{p}<0.05)$. 
cod liver oil (Chang et al., 2010), lard (Kim et al., 2007) and also egg yolk (Jung et al., 2005). In the present study, the optimum conditions of five different factors (crosslinked $\beta-\mathrm{CD}$ concentration, mixing temperature, mixing time, mixing speed and centrifugal speed) were examined in cholesterol removal from whole eggs using crosslinked $\beta$-CD. It was found that $25 \%$ crosslinked $\beta-C D$ was a sufficient amount to remove cholesterol effectively from whole egg. The percentage of cholesterol removal decreased when $30 \%$ crosslinked $\beta-C D$ was used, because an excess of $\beta$-CD could compete with each other to bind to cholesterol molecules (Micich, 1990). It was also reported that cholesterol- $\beta-C D$ complex in egg yolk became unstable above $40^{\circ} \mathrm{C}$, when $80 \%$ of cholesterol dissociated from $\beta-C D$ (Kwak et al., 2001). According to the results, it can be concluded that the cholesterol removal showed a declining trend when mixing temperature was set higher than the optimum temperature $\left(40^{\circ} \mathrm{C}\right)$. In addition, the decrease in cholesterol removal after $30 \mathrm{~min}$ of mixing time could be related to instability of an inclusive cholesterol- $\beta$ CD compound over a longer mixing time (Chang et al., 2010). A study (Jung et al., 2005) showed that the removal was in the range of $75.9 \%$ to $91.6 \%$ when egg yolk was mixed with $20 \%$ crosslinked $\beta-\mathrm{CD}$ at $40^{\circ} \mathrm{C}$ for $30 \mathrm{~min}$ and that a centrifugal speed at 2,210 to $5,470 \times \mathrm{g}$ had no significant effect on removal rate, therefore, they stated that mixing and centrifugal speeds may not play an important role on cholesterol removal rate from egg yolk. This result agrees with the present study showing over $85 \%$ cholesterol removal from whole egg with different mixing and centrifugal speeds, so it can be assumed that the mixing speed and centrifugal speed may not be the important factors in this process. Thereby, the optimum condition for cholesterol removal could vary with different food products.

In whole eggs, egg white consists of a solution of about $10 \%$ protein, containing more than 40 different kinds of proteins. Egg yolk consists of nearly $17 \%$ protein (Mine, 2007). A review has described studies of the binding of cyclodextrin to protein, and almost all studies have identified amino acid residues as the main structural element interacting with cyclodextrin. So, it can be assumed that the crosslinked $\beta-C D$, which is only a product of a crosslinking reaction between $\mathrm{C}-2$ position of $\beta-\mathrm{CD}$ and one of the carboxyl groups of the crosslinking agent (Kwak et al., 2011), could combine with cholesterol from egg yolk as well as bind to amino acid residues from egg protein. If it is so, it can explain why the cholesterol removal efficiency of the crosslinked $\beta$-CD for recycling is low in present study. By contrast, a similar study stated that over $80 \%$ cholesterol removal rate from egg yolk diluted with water was obtained when crosslinked $\beta$-CD was reused up to 8 times used with no significant difference $(\mathrm{p}<0.05)$ between each removal
(Jung et al., 2005). In the present study, as the number of repetitive uses of the crosslinked $\beta-C D$ was increased, the $\beta-\mathrm{CD}$ bound to more egg protein from whole egg; as a result, cholesterol removal ability of crosslinked $\beta-C D$ was reduced. Therefore, the cholesterol removal efficiency of crosslinked $\beta-C D$ decreased significantly at the last two recycles, and the recyclable yield of the crosslinked $\beta-C D$ also increased accordingly when the $\beta-\mathrm{CD}$ was used many times.

In conclusion, this study indicated that the optimum conditions of cholesterol removal were $25 \%$ crosslinked $\beta-\mathrm{CD}, 40^{\circ} \mathrm{C}$ mixing temperature, $30 \mathrm{~min}$ mixing time, 1,200 rpm mixing speed and $2,810 \times g$ centrifugal speed. Moreover, the crosslinked $\beta-C D$ could not be applied into whole egg in the cholesterol removal process with an effective recycling. Further study about the binding of the crosslinked $\beta-C D$ to components in egg will be necessary in future.

\section{ACKNOWLEDGEMENTS}

This study was supported by Ministry for Food, Agriculture, Forestry and Fisheries funded by the Korean Government (311029-03-2-HD110).

\section{REFERENCES}

Adams, M. L., D. M. Sullivan, R. L. Simth, and E. F. Richter. 1986. Evaluation of direct saponification method for determination of cholesterol in meats. J. Assoc. Offic. Anal. Chem. 69:844-846.

AOAC. 2000. Official Methods of Analysis. 10th edn. Association of Official Analytical Chemists, Washington DC, USA.

Brown, W. V. 1990. Dietary recommendation to prevent coronary heart disease. Ann. NY Acad. Sci. 598:376-388.

Chang, Y. H., J. E. Lee, and H. S. Kwak. 2010. Optimization of the condition for removing cholesterol from cod liver oil by $\beta$ cyclodextrin crosslinked with adipic acid. J. Am. Oil Chem. Soc. 87:803-808.

Cully, J. and H. R. Vollbrecht. 1990. Process for the removal of $\beta$-cyclodextrin from egg yolk. US. Patent NO. 5292546.

Frioriti, J. A., J. S. Rex, and H. Clifford. 1978. Low cholesterol egg product and process. US. Patent No. 4103040.

Griffin, H. D. 1992. Manipulation of egg yolk cholesterol: A physiologist's view. World's Poult. Sci. J. 48 :101-112.

Haberstroh, C. and C. E. Morris. 1991. Fat and cholesterol reduced foods. 1st edn. Gulf Publ. Co. Houston TX, USA.

Han, E. M., S. H. Kim, J. Ahn, and H. S. Kwak. 2007. Optimization cholesterol removal from cream using $\beta$-cyclodextrin crosslinked with adipic acid. Int. J. Dairy Technol. 60:31-36.

Hargis, P. S. 1988. Modifying egg yolk cholesterol - A review. World's Poult. Sci. J. 44:17-29.

Jung, T. H., H. S. Park, and H. S. Kwak. 2005. Optimization of cholesterol removal by crosslinked $\beta$-cyclodextrin in egg yolk. Food Sci. Biotechnol. 14:793-797. 
Kim, S. H., H. Y. Kim, and H. S. Kwak. 2007. Cholesterol removal from lard with crosslinked $\beta$-cyclodextrin. Asian-Aust. J. Anim. Sci. 20:1468-1472.

Kim, S. H., J. Ahn, and H. S. Kwak. 2004. Crosslinking of $\beta$ cyclodextrin on cholesterol removal from milk. Arch. Pharm. Res. 27:1183-1187.

Kwak, H. S., H. M. Suh, J. Ahn, and H. J. Kwon. 2001. Optimization of $\beta$-cyclodextrin recycling process for cholesterol removal in cream. Asian-Aust. J. Anim. Sci. 14:548-552.

Kwak, H. S., J. E. Lee, and Y. H. Chang. 2011. Structural characterization of $\beta$-cyclodextrin crosslinked by adipic acid. Int. J. Food. Sci. Tech. 46:1323-1328.

McNamara, D. J. 2000. The impact of egg limitations on coronary heart disease risk: Do the Numbers Add up? J. Am. Coll. Nutr. 19:540S-548S.

Melnick, D. 1971. Low cholesterol dried egg yolk and process. U. S. Patent No. 3563765.
Merchant, Z. M., G. G. Anikumar, and R. G. Krishnamurthy. 1991. Functional decholesterolized egg yolks. US Patent No. 5037661.

Micich, T. J. 1990. Behavior of polymer supported digitonin with cholesterol in the absence and presence of butter oil. J. Agric. Food. Chem. 38:1839-1843.

Mine, Y. 2008. Egg Bioscience and Biotechnology. 1st edn. John Wiley and Sons, Inc., Hoboken, NJ, USA.

Rahkovsky, I. and C. A. Gregory. 2013. Food prices and blood cholesterol. Econ. Hum. Biol. 11:95-107.

SAS. 2002. User's Guide: Statistics, Version 9 Edn. SAS Institute Inc, Cary, NC, USA.

Shin, J. Y., P. Xun, Y. Nakamura, and K. He. 2013. Egg consumption in relation to risk of cardiovascular disease and diabetes: A systematic review and mata-analysis. Am. J. Clin. Nutr. 98:146-159.

Smith, D. M., A. C. Awad, M. R. Bennink, and J. L. Gill. 1995. Cholesterol reduction in liquid egg yolk using $\beta$-cyclodextrin. J. Food. Sci. 60:691-694. 